\title{
A "CONQUISTA DA TERRA": (RE) PRODUÇÃO SOCIAL E (RE)CONSTRUÇÃO HISTÓRICA ENTRE AGRICULTORES FAMILIARES DO MUNICÍPIO DE ARAPONGA - MG *1
}

Marisa Alice Alves

\section{Introdução}

Este trabalho é construído a partir da pesquisa realizada no município de Araponga, localizado na Zona da Mata mineira, aliando reconstrução histórica e trabalho de campo etnográfico. ${ }^{2}$ Nesse município, um grupo de agricultores familiares desenvolve, desde 1979, um meio original de acesso à terra, o qual denominam "conquista da terra". Esta consiste em uma forma de compra em conjunto de terras a partir de trocas e empréstimos de produtos agrícolas, no interior de um grupo centrado em valores comuns e laços de parentesco e vizinhança.

Para fins analíticos, a "conquista da terra" é considerada, em primeiro lugar, um processo através do qual os agricultores familiares de Araponga relacionam-se com a história de ocupação da terra na região, ao recriá-la por meio da memória coletiva em termos de uma história-mito, e ao construírem sua identidade com referência a essa história. Em segundo lugar, a "conquista da terra" é considerada um mecanismo de reprodução social engendrado pelos agricultores familiares de Araponga e que se faz, portanto, segundo o conjunto de valores camponeses desses agricultores, reiterando-os ao longo do tempo, o que permite a reprodução de uma condição camponesa entre eles.

\section{A conquista da terra}

O processo de "conquista da terra" iniciou-se em 1979 com a chegada das Comunidades Eclesiais de Base (CEBs) à região de Araponga. Segundo entrevistados, "tudo começou com as CEBs" e foi a partir daí que os agricultores foram "conscientizados" e passaram a se "organizar". 
As CEBs constituem o eixo de atuação da Igreja Católica a partir do Concílio Vaticano II, sobretudo junto às camadas "populares" na América Latina. O princípio teológico que orienta suas práticas, denominado "Teologia da Libertação", busca a conciliação da fé cristã com uma práxis libertadora, na qual se compreende "a história humana como uma única história de libertação-salvação e de opressão-perdição" (Iokoi 1996:214). O discurso das CEBs constitui-se em torno da pregação de uma história da humanidade que deveria tender à liberdade, sendo que esta acabaria com a "violência que se manifestava na exploração e na dominação de classe exercida pelos opressores que expropriavam os oprimidos" (Iokoi 1996:46).

Argumento que a história da região de Araponga, apreendida por meio da memória coletiva dos agricultores, apresenta-se sob o signo da oposição violência/ resistência. Nesse sentido, as formulações das CEBs a respeito da história humana, em sentido amplo, são interpretadas a partir da perspectiva dos agricultores a respeito de sua própria história, havendo uma confluência de dois modos de conceber o tempo histórico. Assim, a inserção bem-sucedida das CEBs entre os agricultores familiares de Araponga fazse por meio da consonância de discursos e práticas desta instituição com valores e concepções locais. Dessa forma, poder-se-ia dizer que as CEBs funcionam como uma espécie de catalisador de processos sociais, como os que deram origem à "conquista da terra", presentes no contexto sociocultural dos próprios agricultores.

A idéia que deu origem à "conquista da terra" foi criada por três irmãos - Neném, Bibim e Fizim - em uma noite quando caminhavam para casa depois de lerem e de discutirem a Bíblia em uma reunião das CEBs. Segundo seu Neném, essa idéia consistia em inverter uma passagem bíblica, a qual relata que os apóstolos venderam suas posses e colocaram tudo em comum. Em lugar de vender, seu Neném e seus irmãos resolveram comprar, pois perceberam que sua "realidade era outra" e "só rezar, sem obras, é tempo perdido, é morte, tem que partir para uma ação", como afirma o entrevistado. Criaram, então, a "conquista da terra" como um mecanismo de ajuda mútua por meio do qual um grupo de agricultores interessado em adquirir sua terra reúne-se a partir de laços de solidariedade, seja de parentesco, seja de amizade ou vizinhança, para que todos ajudem cada um, por sua vez, a comprar a terra.

No interior do grupo todos disponibilizam algum produto agrícola, principalmente o café, recebem empréstimos — também em produtos - de amigos, vizinhos e parentes, vendem os produtos e compram a terra à vista. Esta é então dividida entre as famílias participantes, havendo casos em que, apenas temporariamente, a terra permanece em conjunto, sendo trabalhada coletiva- 
mente. A produção advinda dessa terra servirá para pagar os empréstimos que, da mesma forma como foram recebidos, ou seja, em produtos, serão pagos na mesma quantidade, independente de atualizações do valor monetário.

No decorrer desse processo de compra de terras, foi criado, em 1987, o Centro de Tecnologias Alternativas da Zona da Mata (CTA), uma organização não-governamental de cunho ambientalista. Segundo publicação do CTA, a criação da entidade foi fruto de uma ação conjunta de técnicos e agricultores, na qual "embora os sonhos não fossem os mesmos, os valores que os sustentavam eram comuns" (CTA 2002:3).

A partir do início do trabalho do CTA junto aos agricultores familiares de Araponga, passou-se a vincular a "conquista da terra" à construção de um novo modelo produtivo baseado na agroecologia. Por um lado, a posse das terras por parte dos agricultores é considerada condição sine qua non pelo CTA para o exercício de suas atividades, já que esta entidade propõe um modelo de produção agroecológica baseado na pequena propriedade trabalhada pela mão-de-obra familiar. Por outro lado, os agricultores passaram a considerar fundamental a atuação do CTA para viabilizar a produção nas novas pequenas propriedades.

Segundo o CTA, sua atuação bem-sucedida junto aos agricultores foi condicionada pela existência de valores e objetivos comuns. Para um dos agricultores, seu Neném, "a gente [os agricultores] já tinha a idéia, mas ele [o CTA] acabou ajudando a acelerar mais a idéia". Essa "idéia" de que fala seu Neném refere-se à implementação de um modelo de produção "sem veneno", na definição dos agricultores, ou "agroecológico", na acepção dos técnicos do CTA.

A partir daí, argumento que a inserção do CTA entre os agricultores se deu (e se dá) de modo semelhante ao que ocorre com as CEBs, ou seja, devido à confluência de concepções e práticas de ambos. No entanto, se com as CEBs essa confluência poderia ser localizada sobretudo no plano das concepções a respeito do tempo histórico, no caso do CTA essa confluência se dá, primeiramente, no plano das concepções a respeito da natureza. Dessa forma, o CTA funcionaria também como um catalisador para a efetivação já presente de um modo específico de plantar, de se relacionar com a terra, com a natureza, ainda que não completamente evidente entre os agricultores familiares de Araponga.

Desde o início da "conquista da terra", em 1979, até o ano de 1989, não havia qualquer documentação referente aos empréstimos para as compras de terra, já que "era tudo na base da confiança", como dizem vários agricultores. Em 1989, foi criado o Sindicato de Trabalhadores Rurais do Município de Araponga pelos mesmos agricultores que estavam envolvidos no princípio 
da "conquista da terra" e, segundo eles, da mesma forma que esta o foi, devido à "conscientização das CEBs".

Desse momento em diante, a "conquista da terra" institucionaliza-se, sendo gerida pelo sindicato. No entanto, seus princípios tentam manter-se os mesmos, como busco demonstrar. O processo para a compra de terras a partir de então é dirigido pelos seguintes procedimentos: 1) o agricultor interessado em comprar sua terra deve procurar o sindicato, no qual há uma comissão incumbida de gerenciar o processo; 2) a comissão analisa o "perfil" do interessado segundo os princípios denominados "Dez mandamentos da conquista de terra em conjunto"; 3) caso ele se enquadre no "perfil" prescrito pelos "dez mandamentos", o agricultor deve disponibilizar qualquer recurso que eventualmente possua para a compra da terra; 4) o agricultor recebe um empréstimo em dinheiro, mas calculado e anotado como se fosse uma determinada quantidade de sacas ou arrobas de café correspondente àquele valor, para "inteirar" o que já possui; 5) o agricultor compra sua terra à vista de acordo com a oferta no mercado fundiário local, por meio do dinheiro que recebeu do sindicato; 6) passados dois anos da data do empréstimo, o agricultor deve pagá-lo com a mesma quantidade de sacas ou arrobas de café anotada no sindicato, independente de alterações no valor do produto no mercado. Além disso, as compras são feitas normalmente em grupos, devido à grande extensão das propriedades compradas, que são dividas entre as famílias envolvidas em um mesmo processo de aquisição.

Os "dez mandamentos", enumerados adiante, expressam os valores dessa coletividade de agricultores e, segundo eles, devem ser aceitos por todos aqueles que queiram adquirir sua terra. Afirmo que tais valores são constitutivos do ethos camponês da coletividade, na medida em que informam sobre uma moral camponesa aí presente, condição sine qua non para a realização de um modo de vida também camponês, tanto antes quanto após a compra. Tais mandamentos, conforme sistematização feita pelo CTA (2002:26), são os seguintes:

1. Interesse pela terra: ter amor pela terra e compromisso;

2. Comportamento no grupo: ter sinceridade, não mentir, não tomar decisões individualistas, participar de reuniões;

3. Meio ambiente: ter consciência ecológica;

4. Divisão: formar um grupo responsável e não tomar decisões precipitadas;

5. Conquista das terras: fazer economia para comprar terra, ter em mente que isso é possível e viver em sintonia com a comunidade;

6. Forma de convivência: ter diálogo e consideração com os companheiros, tratar dos assuntos que envolvem a família, participação e reflexão religiosa em grupos, independentemente da seita; 
7. Participação e contribuição da mulher: lutar e animar o companheiro, exigir seu nome nos documentos, não ter vergonha de ser lavradora, participação na partilha das terras, participação nas decisões em grupo;

8. Participação agrícola: participação nas trocas de serviço e mutirão, recuperação e conservação do solo, visitar as propriedades dos companheiros, usar leguminosas; 9. Maneiras de usar as coisas móveis do grupo: usar tração animal para os serviços do grupo, uso dos animais por pessoas acostumadas com esse trabalho, reconhecer as necessidades maiores de serviços, ter zelo com os animais;

10. Maneiras de usar os imóveis: conservar e ampliar as estradas, manter trilhas, usar e oferecer estruturas, como moinho, engenho, olaria, usina, manter torneiras fechadas quando a água for pouca, controlar seus pequenos animais para não prejudicarem a propriedade vizinha.

Em 1998, em visita à região, membros da Fundação Ford, interessados em projetos desenvolvidos pelo CTA, tomaram conhecimento da experiência da "conquista da terra" e encaminharam um pedido de apoio ao projeto para a entidade. Este foi aprovado, o que propiciou a doação para o sindicato de 30 mil dólares, quantia que passou a constituir um fundo rotativo para a compra de terras. O fundo possibilitou a ampliação da experiência, garantindo os empréstimos, agora documentados, mas ainda calculados na "moeda-produto" local, ou seja, arrobas de café.

Da mesma forma que anteriormente, com os poucos recursos do sindicato e segundo os mesmos princípios desde o início da experiência, é feita a "organização" para a "conquista da terra" ainda hoje. O agricultor interessado procura o sindicato, requisita a quantia correspondente às arrobas de café de que necessita para "inteirar" o que já possui para comprar sua terra. O sindicato calcula então o valor monetário daquela quantidade pela cotação do preço do café no dia, emprestando o dinheiro para o agricultor sob documentação. Este, após dois anos, deverá pagar o empréstimo mediante a mesma quantidade de café que recebeu, independente de o produto possuir um valor maior ou menor no mercado naquele dia. De acordo com seu Neném, "graças a Deus todo mundo pagou, e até antes do prazo".

Até a data da última visita a campo, em janeiro de 2005, haviam sido "assentadas" aproximadamente 110 famílias, em uma área total de cerca de 500 hectares. ${ }^{3}$ Este fato tem sido considerado por muitos, inclusive por membros do Ministério do Desenvolvimento Agrário (MDA), em uma visita em janeiro de 2005 à região, como uma experiência de "reforma agrária alternativa". Muitos agricultores resistem em considerar sua realização como um modelo de reforma agrária, considerando-a simplesmente como "um jeitinho que a gente deu de conseguir terra", uma "conquista da terra", enfim. Esta seria, 
segundo eles, diferente da reforma agrária, porque conseguida com esforço próprio pois, como afirma seu Neném, "aquilo que a gente consegue com o suor do rosto, dá mais valor e não abandona de jeito nenhum".

\section{De primeiro}

A "conquista da terra", como descrita anteriormente, é um processo por meio do qual os agricultores que dele fazem parte relacionam-se com a história da ocupação da terra na região de Araponga - à qual hoje corresponde o município de Araponga - localizada entre as bacias dos rios Doce, Paraíba do Sul e Casca, inicialmente coberta pelo bioma Mata Atlântica, hoje reduzido a apenas 7,6\% da cobertura original. Até meados do século XIX, a área era ocupada predominantemente por povos indígenas - o principal grupo formado pelos Puri, que habitavam a região entre as serras da Mantiqueira e do Mar e que foram completamente exterminados.

Com a descoberta do ouro no início do século XIX, foi formada uma povoação que se tornaria, em 1962, o município de Araponga, e começaram a chegar à região os primeiros escravos negros para trabalharem nas minas. Também a partir dessa época surgem alguns grupos de negros refugiados, como afirma Mello (2002:70),

[...] em razão da proximidade com a Estrada Real, que servia ao transporte de metais preciosos vindos de Ouro Preto, passando por Santa Rita do Turvo (atual Viçosa) em direção a São João Batista do Presídio (atual Visconde do Rio Branco). O trânsito e o corte de árvores fora da estrada eram proibidos com o objetivo de evitar roubo ou contrabando dos metais que por ali passavam, o que favoreceu o estabelecimento dessa população negra.

Em meados do século XIX, já com a decadência da exploração do ouro, a cafeicultura é introduzida na região, inicialmente com a formação de grandes fazendas trabalhadas por mão-de-obra escrava. Em um momento posterior, segundo Campos \& Mendes (2004):

[...] com a transição para o trabalho livre, frente à indisponibilidade de um contingente de trabalhadores assalariados facilmente controlável, a produção cafeeira foi organizada a partir de formas de relação de trabalho que davam acesso parcial ao uso da terra pelos trabalhadores, como o colonato, através da meação.

Alguns desses colonos, que conseguiram ter acesso à sua própria terra, 
deram origem às atuais pequenas propriedades familiares. Além disso, algumas das antigas fazendas foram sendo desmembradas devido a sucessivas crises na cafeicultura e a divisões por herança. Também em razão das crises, a produção agrícola da região foi diversificada e os pequenos produtores passaram a se dedicar à agricultura voltada prioritariamente ao consumo familiar.

Em sua análise sobre a estrutura fundiária de Araponga, Campos \& Mendes (2004) afirmam que:

[...] atualmente a região é composta por micro e pequenas propriedades onde se produz feijão, milho, arroz, cana-de-açúcar, café e gado. Segundo dados do IBGE (1996) para a região de Araponga, as pequenas propriedades com até 50 hectares representavam 85\% do total de estabelecimentos (544 unidades), mas detinham apenas $37 \%$ da área. As médias e grandes propriedades, $15 \%$ dos estabelecimentos (90 unidades), ocupavam 63\% da área. Neste contexto, a fragmentação da propriedade da terra é acompanhada de uma distribuição bastante desigual de recursos. Grande parte dos trabalhadores rurais não tem acesso à terra, a não ser por meio da meação e do arrendamento, e os pequenos agricultores não têm terra suficiente para a reprodução da unidade familiar.

No processo descrito, a ocupação da terra na região de Araponga constitui a "história social da terra" e de seus significados para os grupos que com ela estabelecem diferentes tipos de relação. Do mesmo modo que Ianni (1979), ao utilizar o conceito de "história social da terra", o que se analisa aqui é o processo de ocupação da terra que mobiliza as relações sociais e traz diferentes significados para grupos diversos que com ela se relacionam.

Partindo-se de uma observação espaço-temporal, baseada tanto em material escrito - seja ele oficial ou não - quanto na história oral, surgem os significados sociais da terra para os diferentes grupos que ao longo de sua história estão envolvidos em relações entre si e com a própria terra. Portanto, a proposição do autor de que "a idade da terra é a mesma idade dos homens, da sociedade dos homens, das distintas formas sociais de organizar a produção" (Ianni 1979:230) é fundamental para a compreensão do processo de ocupação da terra na região de Araponga e da forma com que os agricultores familiares que ali vivem interagem com esse mesmo processo por meio da "conquista da terra".

Os agricultores reconstroem o processo histórico descrito por meio da "memória coletiva", em termos de uma história-mito marcada pela oposição violência/resistência da qual o grupo se considera herdeiro. ${ }^{4}$ Os antigos índios e negros, de quem os pequenos agricultores consideram-se descendentes, são exemplos dessa dualidade e estão presentes nas narrativas de tais agri- 
cultores como vítimas de violência, mas que de algum modo desenvolveram formas próprias de resistência. Nesse sentido, as histórias dos índios e dos negros são consideradas como inspiração para a idéia que dá origem à "conquista da terra", como nos conta Paulinho, um agricultor da região:

Quando a gente iniciou esse trabalho, a gente não tinha intenção de contar isso, divulgar pra ninguém, chamava "segredo de índio", na época. Porque índio é uma pessoa que fica lá no mato, uma pessoa que às vezes fica à margem da sociedade desenvolvida, aí então eles têm o segredo deles. É, segredo de índio, porque a gente é descendente de índio; fazer a coisa do índio. A avó da minha mãe era índia, era dos Puri daqui. Então, a avó da minha mãe era a tal "pega no laço", que eles falam, né, que nem de primeiro.

Essa "memória coletiva", quando relembrada e contada, é introduzida por um "de primeiro..." ou "de primeiro era assim...", que remete ao tempo histórico-mítico de suas origens. Lucília Neves advoga que memória e história são suportes para as identidades individuais e coletivas, pois o relembrar do indivíduo relaciona-se à sua inserção histórica e social (Neves 2000:110). Portanto, a memória dos agricultores de Araponga apresenta a reconstrução do processo de ocupação da terra na região em termos de uma história-mito marcada pela dualidade violência e resistência. A inserção dos agricultores em tal processo histórico e no passado mítico faz-se por meio da "conquista da terra" que, dessa forma, é considerada um meio de resistência desenvolvido por aqueles que teriam sido vítimas da violência de uma estrutura agrária desigual. Nesse sentido, a terra é o próprio signo de resistência, é aquele que realiza a conexão interna ao próprio grupo - formado pelos que a conquistaram - e deste com o seu passado mítico.

Ao reformularem o processo de ocupação da terra, como afirmado, os agricultores de Araponga constroem sua identidade a partir da imagem que fazem de si próprios e dos valores que compartilham em oposição aos "outros" — os "grandes". Isto se deve ao fato de que a história da região, na perspectiva desses agricultores, ao ser marcada pela dualidade violência/resistência, é necessariamente representada por dois grupos — de um lado, os "grandes", os opressores; de outro, os "pequenos", as vítimas da violência exercida pelos primeiros, mas atores de processos de resistência. ${ }^{5}$ Assim, os agricultores envolvidos na "conquista da terra" são os "pequenos", constituindo um grupo coeso, centrado em valores que são a condição para a efetivação da "conquista da terra", ao mesmo tempo em que são reiterados por ela. 


\section{Os pequenos: família, terra e trabalho}

A "conquista da terra" faz-se por meio do conjunto de valores camponeses desses "pequenos" e os expressa através de seus princípios diretores, reiterando-os ao longo de sua efetivação. Esses valores estão centrados essencialmente na família, na terra e no trabalho, elementos essenciais da organização social dos agricultores familiares de Araponga.

O primeiro de tais elementos é a família, que comporta duas dimensões: uma referente às relações de parentesco; outra, às relações de produção. ${ }^{6}$ Inicialmente, é dentro do grupo de parentesco que se dão as transações necessárias à "conquista da terra"; nele, parentes emprestam produtos uns aos outros, sem contabilizarem monetariamente o valor desses empréstimos, para que todos possam adquirir o próprio patrimônio.

Além disso, sendo o parentesco uma linguagem que fala do uso e da posse da terra na área estudada, a "conquista da terra" implica a possibilidade, ao longo do tempo, da reprodução desse patrimônio no interior do grupo de parentesco em que se está inserido e, portanto, da perpetuação do modelo de relações de parentesco vigente. Dessa maneira, pode-se afirmar que as relações sociais entre os agricultores envolvidos com a "conquista da terra" estão baseadas na solidariedade fundada na ideologia do parentesco, o que implica prestações e obrigações morais mútuas. Isto é afirmado nos "dez mandamentos", ao se referir a um tipo de comportamento que se destina aos parentes nessa área - a "consideração".

Dessa forma, a importância do parentesco neste estudo refere-se ao fato de ser ele condição para a reprodução social do campesinato. A "conquista da terra" é a base da estratégia de reprodução adotada por esses "camponeses"; nela, o patrimônio, não apenas material, é reproduzido ao longo do tempo.

Em segundo lugar, a família é compreendida como um elemento organizador da produção camponesa, já que o processo produtivo se dá na unidade familiar e envolve todos os seus membros de maneira hierárquica. Essa unidade produtiva e de consumo compreende as atividades domésticas e as agrícolas, realizadas, respectivamente, na "casa" - espaço feminino por excelência - e na "roça" - espaço masculino. ${ }^{7}$ Além da hierarquia de gênero, há a divisão do trabalho familiar por idade. Assim, os filhos entram no processo produtivo de diversas maneiras segundo a sua faixa etária, como afirmam Woortmann \& Woortmann (1997:47):

O número de filhos conduz a uma contradição: são força de trabalho, mas são também herdeiros; num momento possibilitam a produção-reprodução e, em cer- 
tos momentos do ciclo evolutivo, tornam possível a produção de um excedente. Noutro momento, como herdeiros, podem levar a reprodução do campesinato à crise, pelo excessivo fracionamento da terra.

O segundo elemento, a terra, é um fator essencial para a reprodução da condição camponesa e disso decorre a extrema importância dada a ela no discurso local, no qual se expressa a relação com ela em termos de uma troca respeitosa, o que constitui o mais importante dos mandamentos - ter amor pela terra. Esta não possui apenas valor monetário, mas valor moral, e ter acesso à terra é condição de liberdade diante dos "grandes". Portanto, a relação homem-natureza nessa área é de troca e respeito, baseada na construção e na aplicação de um "saber" específico; nele, "ecologia e simbolismo não são, pois, dimensões separadas" (Woortmann \& Woortmann 1997:132).

Diretamente relacionado à terra está o trabalho, terceiro elemento, outro valor essencial desse universo. O trabalho é uma categoria central, incluída em um campo moral que também contém a terra e, por isso, os mesmos valores aplicáveis a ela também o são ao trabalho, como as noções de troca e respeito, os saberes necessários à sua realização e à sua imprescindibilidade. Além disso, o trabalho pressupõe a terra para a sua realização e é condição para que ela seja adquirida, já que é por meio do produto desse trabalho que a terra é comprada.

Dessa forma, o trabalho é o elemento mediador "por natureza" nesse universo, visto como uma categoria moral essencial, pois permite a realização da condição camponesa de forma plena. Devido a isso, o mandamento considerado como segundo em ordem de importância diz respeito ao valor do trabalho, e todos os esforços devem ser revertidos para a compra da terra.

A partir da terra, do trabalho e da família dá-se o próprio processo de trabalho que, entre os agricultores familiares de Araponga, visa essencialmente à subsistência da unidade familiar. No entanto, o principal produto da região, o café, não é destinado de imediato ao consumo da unidade familiar. Segundo o relato do agricultor João Donizete, "o café é o salário", isso porque ele é produzido em primeiro lugar para a comercialização e é o que garante aos "pequenos" a renda monetária. Por meio dela é que são possíveis as transações comerciais para a aquisição de outros gêneros para o sustento da casa. O café é um produto que transcende a importância para a subsistência, tendo grande valor ritual. Portanto, as atividades que o cercam — desde o trabalho na "roça" até o seu consumo - são cercadas desse caráter. Além disso, ele é muitas vezes permutado entre os próprios agricultores, sendo o objeto das trocas e dos empréstimos envolvidos na "conquista da terra". Devido a isso, o café é considerado "moeda" e "medida de todas as coisas" na região. 
Os valores dos agricultores familiares de Araponga, fundados na família, na terra e no trabalho, são as diretrizes da "conquista da terra" e estão expressos no seu princípio organizador — os "dez mandamentos" — reiterados pelos agricultores no decorrer do processo de aquisição da terra. Dessa forma, não se pode compreender a "conquista da terra" senão no interior do universo cultural e de organização social dos agricultores de Araponga e ao longo de sua história.

\section{Conclusão}

Conforme os argumentos apresentados no decorrer deste trabalho, em primeiro lugar, a "conquista da terra" deve ser compreendida em referência à memória dos próprios agricultores, pois é ela que cria a sua identidade e realiza a inserção destes no processo de ocupação da terra na região. Em segundo lugar, a "conquista da terra" somente possui significado ao fazer parte do complexo de valores do grupo de agricultores de Araponga, pois é uma práxis que permite a reprodução do seu modo de vida.

Dessa forma, a "conquista da terra" pode ser considerada como um meio de identificação e de atuação essencialmente político desenvolvido pelos agricultores familiares de Araponga, comportando uma perspectiva sobre o tempo histórico ao relacionar a visão de um passado histórico-mítico e a construção dos tempos presente e futuro de suas vidas. Além disso, a "conquista da terra" é uma forma de (re)produção social de uma condição camponesa entre esses agricultores, pois não apenas reproduz, mas produz essa condição. A conquista resgata o elemento essencial do ser camponês - a terra — a partir de valores que, além de não terem deixado de ser camponeses, foram reforçados após a conquista.

Tanto como instrumento político quanto mecanismo de reprodução social, a "conquista da terra", considerando seu efetivo sucesso, é um mecanismo que permite a (re)produção de uma condição camponesa segundo o conjunto de valores e o processo histórico analisados. A sua possível expansão e aplicação a outras realidades sociais não deixa de suscitar sonhos e expectativas entre os idealizadores da "conquista da terra", como seu Neném:

E que isso avance. O bom era que isso espalhasse para o mundo inteiro, porque eu acho que todo mundo que trabalha na terra, na visão da gente, tem que ter a terra dele. A pessoa que tem coragem de pegar no cabo de uma ferramenta para cultivar a terra, a gente não abre mão disso, não. Apesar de que muita gente ainda não tem acesso à terra. De que maneira, não importa, tem que ser do nosso jeito não, tem que ser de qualquer maneira possível, mas que tem que ter isso, tem que ter. 
Recebido em 04 de setembro de 2006

Aprovado em 21 de setembro de 2006

Marisa Alice Alves é mestranda no Programa de Pós-Graduação em Antropologia da Universidade Federal de Minas Gerais. E-mail: <marisalves29@ yahoo.com.br>

\section{Notas}

" Nota do editor - Este artigo foi apresentado na XXV Reunião Brasileira de Antropologia, da Associação Brasileira de Antropologia (ABA), realizada em Goiânia, em 2006, tendo recebido um dos três primeiros prêmios no Concurso Claude Lévi-Strauss para Pesquisas de Graduação (Modalidade B - Comunicações Coordenadas).

${ }^{1}$ Este artigo é uma versão reduzida de meu trabalho de conclusão do curso de graduação em Ciências Sociais da Universidade Federal de Minas Gerais, realizado sob a orientação da professora Deborah de Magalhães Lima. Agradeço a ela pela orientação tão dedicada, e aos agricultores e agricultoras de Araponga pela acolhida incondicional.

${ }^{2}$ Nesse sentido, a abordagem busca aproximar-se da realizada por Ellen Woortmann (1995), em que a autora propõe uma relação que considera fundamental - entre etnografia e historiografia - na qual a temporalidade é imprescindível. Segundo a autora, "a temporalidade é por mim tratada levando em conta, de um lado, a inserção desses grupos em processos macro-históricos (regionais, nacionais ou internacionais) e, de outro, como construtores de sua própria história, inclusive de uma história-mito, e de uma micro-história" (Woortmann 1995:16).

3 O módulo rural de Araponga corresponde a 28 hectares, segundo dados do INCRA (1998). O Estatuto da Terra de 1964 define módulo rural como a área necessária à subsistência da unidade familiar. No entanto, segundo os agricultores da região, a área necessária à reprodução de suas famílias varia entre 1 e 3 alqueires (entre 3 e 9ha). Essa discrepância pode ser analisada levando-se em conta os diferentes códigos segundo cada realidade local, como em Moura (1978:47), em que "os costumes simplificam ou ignoram a lei".

${ }^{4}$ O conceito de "memória coletiva" é utilizado aqui no sentido atribuído ao termo por Halbwachs (1990), em que há necessariamente um grupo bem definido como suporte dessa memória e em relação com um espaço específico. No caso estudado, esse grupo é formado pelos agricultores familiares de Araponga envolvidos com a "conquista da terra", organizados no interior do espaço das comunidades, em relação íntima com a terra. Além disso, como afirma Halbwachs (1990:71-82), "a lembrança 
é em larga medida uma reconstrução do passado com a ajuda de dados emprestados do presente, [...] já que retém do passado somente aquilo que ainda está vivo ou capaz de viver na consciência do grupo". Nesse sentido, compreende-se a inserção do grupo de agricultores de Araponga no processo de ocupação da terra na região por meio de sua reconstrução do passado em termos de uma história-mito e a partir de um fato presente - a "conquista da terra".

${ }^{5}$ As categorias "pequeno" e "grande", no discurso local, evidenciam não um limite mensurável da extensão das propriedades rurais, mas modos de vida e de relação com o meio diferenciados. Dessa forma, "pequeno" designa aqueles que utilizam trabalho familiar, em uma extensão de terra necessária ao sustento da própria família, sendo que esta terra não possui apenas valor de mercado, mas também um conjunto de valores morais — é semelhante à "terra de trabalho", conceituada por Garcia Jr. (1983). Essas categorias expressam, por um lado, dois modos diferenciados de relacionamento com o meio e de organização social, remetendo ao processo histórico de ocupação e formação do espaço nessa região, feito de forma desigual, com concentração da terra nas mãos de poucos — os "grandes" — e, por outro lado, exclusão social da grande maioria — os "pequenos". Além disso, evidenciam a percepção e a construção desse processo por parte dos "pequenos" a partir de seus valores. Assim, "pequeno" designa propriamente o camponês, cujas existência e reprodução têm como condição sine qua non o acesso à terra, em sentido identitário e intergeracional (Moura 1978:2). No entanto, como a categoria é referida a um campo moral, mesmo os agricultores que não possuem sua própria terra, trabalhando como assalariados ou meeiros, podem manter um "ideal camponês" expresso em um conjunto de valores, e assim se considerarem e serem considerados "pequenos". Isto não contraria, pelo contrário, evidencia o caráter essencial da terra para a reprodução social camponesa, já que a manutenção desses valores é que permite a busca de soluções para o problema da falta de terra na região.

${ }^{6}$ A família é aqui tratada como um termo abrangente que comporta duas dimensões: o grupo doméstico, como unidade de produção e consumo (Fortes 1958) e o parentesco. Nesse sentido, segue a orientação de estudos que realizam essa distinção entre as duas dimensões do grupo familiar, como Carneiro (1998), Schneider (2003) e Woortmann (1995).

7 A oposição "casa" e "roça" possui a mesma conotação de "casa" e roçado", em Garcia Jr. (1983), enquanto a expressão "tocar roça" possui significado similar a "botar roçado", no mesmo autor. Assim, o homem é responsável pelo trabalho na "roça", é ele quem "toca a roça", ou seja, organiza o processo produtivo por ser o detentor do saber ou do conhecimento necessário a essa atividade. Nesse sentido, observa-se que apenas homens adultos, os pais de família, forneceram informações a respeito da produção. Enquanto isso, o trabalho feminino separa-se do masculino, restringindo-se ao espaço da "casa", correspondendo à esfera do consumo. As atividades femininas podem ser denominadas trabalho, mas geralmente referem-se a elas como "serviço", uma categoria com significado diverso do trabalho propriamente dito, que é "tocar roça". Esse espaço feminino é considerado complementar e dominado em relação ao masculino, mas ocorre também um nivelamento de sua importância, "fato devido à sua inevitável interdependência" (Moura 1978:19). 


\section{Referências bibliográficas}

CAMPOS, Ana Paula Teixeira de \& MENDES, Fábio Faria. 2004. "Cooperação e confiança: a conquista conjunta de terras entre agricultores familiares de Araponga, Minas Gerais". Ms.

CARNEIRO, Maria José. 1998. Camponeses, agricultores e pluriatividade. Rio de Janeiro: Contra Capa.

CTA - Centro de Tecnologias Alternativas da Zona da Mata. 2002. Revista 15 anos CTA. Viçosa: CTA.

FORTES, Meyer. 1958. "Introduction". In: J. Goody (org.). The developmental cycle in domestic groups. Cambridge: Cambridge University Press. pp. 1-14.

GARCIA JR., Afrânio. 1983. Terra de trabalho. Rio de Janeiro: Paz e Terra.

HALBWACHS, Maurice. 1990. A memória coletiva. São Paulo: Vértice.

IANNI, Otávio. 1979. A luta pela terra: história social da luta pela terra numa área da Amazônia. Petrópolis: Vozes.

INCRA - Instituto Nacional de Colonização e Reforma Agrária. 1998. Estatísticas cadastrais (Site: www.incra. gov.br).
IOKOI, Zilda Márcia Grícoli. 1996. Igreja e camponeses: Teologia da Libertaçãoe movimentos sociais no campo-Brasil e Peru (1964-1986). São Paulo: Hucitec. MELLO, Cláudia de Carvalho. 2002. Educação ambiental no entorno do Parque Estadual da Serra do Brigadeiro. Dissertação de Mestrado, Universidade Federal de Viçosa.

MOURA, Margarida Maria. 1978. Os herdeiros da terra: parentesco e herança numa área rural. São Paulo: Hucitec.

NEVES, Lucília de Almeida. 2000. "Memória, história e sujeito: substratos de identidade". Revista da Associação Brasileira de História Oral, 3:109-116.

SCHNEIDER, Sérgio. 2003. A pluriatividade na agricultura familiar. Porto Alegre: Editora da UFRGS.

WOORTMANN, Ellen. 1995. Herdeiros, parentes e compadres: colonos do sul e sitiantes do Nordeste. São Paulo/ Brasília: Hucitec/EdUnB.

\& WOORTMANN, Klaas. 1997 O trabalho da terra: a lógica e a simbólica da lavoura camponesa. Brasília: EdUnB. 
Resumo

Este artigo aborda a "conquista da terra", desde 1979, realizada por um grupo de agricultores familiares no município de Araponga, na Zona da Mata mineira. O processo de "conquista da terra" consiste em um meio original de redistribuição fundiária, por meio da compra de terras em conjunto, a partir de troca e empréstimo de produtos agrícolas no interior de um grupo centrado em valores comuns e laços de parentesco e vizinhança. Analiticamente, a "conquista da terra" é considerada como um processo de (re)construção da história de ocupação da terra na região e como um mecanismo de (re)produção social engendrados por esses agricultores.

Palavras-chave: Campesinato, Acesso à terra, Reprodução social, Memória social, Zona da Mata mineira.

\section{Abstract}

This article addresses the subject of the "conquista da terra" (the "conquest of land"), which has been undertaken since 1979 by a group of peasant farmers in the municipality of Araponga in the region of Zona da Mata, Minas Gerais. The process of land conquest referred to here is an original form of land redistribution through the communal purchase of lands and intra-group trades and loans of agricultural products. These internal group dynamics are based on common values and familial and neighborly ties. Here, we analyze the "conquista da terra" as a process of (re)construction of the history of the occupation of lands in the region and as a mechanism of social (re)production engendered by the peasant farmers.

Key words: Peasantry, Access to land, Social reproduction, Social memory, Mineiran Zona da Mata. 